\title{
The eco-biological-behavioural perfect storm that follows heavy snowfall
}

\author{
David A. Alter MD PhD
}

- Cite as: CMAJ 2017 February 13;189:E225-6. doi: 10.1503/cmaj.170022

See related article at www.cmaj.ca/lookup/doi/10.1503/cmaj.161064

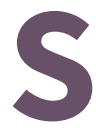

now shovelling has long been known to be an activity that puts particular strain on the cardiovascular system. It incorporates repetitive dynamic aerobic and resistance activity, which induces a Valsalva manoeuvre and places disproportionate workloads on arm rather than leg muscles, resulting in raised heart rate, blood pressure and myocardial oxygen demand. ${ }^{1}$ Such effects are exacerbated by the vasoconstricting and sympathovagal effects of cold-air inhalation, ${ }^{2}$ which together may conspire to precipitate myocardial ischemia, plaque rupture, coronary artery thrombosis or arrhythmias. ${ }^{3}$ Other patient factors such as underlying cardiopulmonary fitness, self-pacing, ${ }^{4}$ circadian variation and the time of snow clearance, ${ }^{5}$ and the use of automated or semi-automated snow removal devices, can further modify cardiovascular responsiveness. ${ }^{1}$

In a linked research study, Auger and colleagues have used routinely collected data to determine an association between the quantity and duration of snowfall and the risks of acute myocardial infarction (MI) in Quebec, Canada, between 1981 and $2014 .{ }^{6}$ Their findings add weight to our understanding that the act of snow shovelling in cold temperatures sets the stage for an eco-biological-behavioural "perfect storm," particularly among those physically deconditioned who have or who are at risk of heart disease. . $^{3,7}$

Auger and colleagues' elegant study incorporates detailed region-specific weather conditions, including daily snowfall and temperature, with individual-level data on hospital admissions and vital statistics. The authors have determined that a heavy snowfall $(20 \mathrm{~cm}$ v. $0 \mathrm{~cm})$ is associated with a $16 \%$ relative increase in the odds of MI-related hospital admission and a $34 \%$ relative increase in the odds of death due to $\mathrm{MI}$ on the day after a snowfall among men. The adverse cardiovascular effects associated with snowfall were not apparent among women. This finding supports their a priori hypothesis that such sex-related differences were largely attributable to snow-shovelling activities, which would more likely be undertaken by men than by women.

This is not the first study to have explored the effects of weather on cardiovascular events. A large body of evidence has established a higher incidence of MI during winter months than

\section{KEY POINTS}

- Heavy snowfall is associated with an increased risk of nonfatal and fatal acute myocardial infarction.

- Snow shovelling puts particular strain on the cardiovascular system.

- Men over 50 years of age who have cardiovascular risk factors or established heart disease and who are physically unfit or habitually sedentary may be at highest risk of myocardial infarction after snow shovelling.

during the summer. ${ }^{5,8}$ However, epidemiologic evidence associating snowfall and $\mathrm{MI}$ has been less consistent., ${ }^{9,10}$ Unlike most other epidemiologic studies, which incorporated aggregate ecologic data, Auger and colleagues used individual-level data and a time-stratified case-crossover study design, whereby each individual was used as his or her own control. Accordingly, weather conditions were the primary factor that differed between cases and controls. For the most part, the authors' use of the casecrossover design eliminates or substantially reduces the effects of confounders - traditional factors known to be associated with an increased risk of nonfatal and fatal MI, such as socioeconomic status, comorbidity and seasonality. Another strength of their study is the consistency in results between the quantity and duration of snowfall. The likelihood of acute MI among men rose with the consecutive number of snow days in a dose-response fashion, and did so in the day that most closely followed the snowfall period, which makes the exposure period closely tied to the outcome and, accordingly, makes causality more plausible. Finally, the authors incorporated a number of sensitivity analyses, which included data restriction to the months of December through February, variations in control days (which came before $\mathrm{MI}$ events) and restrictions to selected regions (e.g., Montréal and Laval), all of which yielded similar results.

As compelling and impactful as these results might be, we must not forget the limitations of the study's observational design. We have no information on snow-shovelling activities, 
patients' symptoms or other behaviours that may have occurred immediately before, during or after snowfall exposure. Misclassification coding errors may have also existed, which may have included trauma (e.g., motor vehicle accident, hip fracture) where myocardial infarction occurred as a complication rather than a primary diagnosis. Periods of heavy snowfall may also have altered patients' health-seeking behaviours, making them less likely to seek urgent medical care had symptoms occurred. ${ }^{11}$

Furthermore, some findings raise questions. For example, the association between quantity of snowfall and MI was similar for men across all age groups. One might have reasonably hypothesized that, had snow shovelling accounted for the adverse events, the odds of cardiovascular events should have risen as the risks of MI, comorbidity and frailty rose. Causal inferences might have been strengthened had the authors explored other "neutral control" or "tracer" conditions for which associations might not have been expected following heavy snowfall exposure periods.

Notwithstanding the interpretative caveats, the potential impact of heavy snowfall on population attributable risk may be nontrivial. Although Auger and colleagues present odds ratios, which overestimate relative risks when events are common, there were nearly 200000 cases of MI (hospital admissions and deaths combined) in Quebec during the months of November through April over the 13-year study period, of which one-third occurred on the day following a snowfall. Even if one were to apply conservative numbers when estimating the relative risks associated with snowfall, the high prevalence of MI during these periods could translate into hundreds of patients sustaining adverse cardiac events each year in Canada.

Does this imply that all patients who have known cardiovascular disease, or those who remain at risk of cardiovascular disease, should avoid shovelling snow? Perhaps it would be wise for men over 50 years of age who have cardiovascular risk factors or established heart disease and who are physically unfit or habitually sedentary to avoid the activity. ${ }^{3}$ At the very least, individuals should be made aware of the risks, particularly with heavy snowfall. Such awareness necessitates broader public health attention. For this reason, we must commend Auger and colleagues for raising awareness of this eco-biological-behavioural perfect storm, so that those living in winter climates can avoid the hazard and experience the fruits that are to come in warmer seasons, at least until the extremely hot and humid days of summer when other eco-biological-behavioural storms may arise.

\section{References}

1. Franklin BA, Hogan $\mathrm{P}$, Bonzheim $\mathrm{K}$, et al. Cardiac demands of heavy snow shoveling. JAMA 1995;273:880-2.

2. Muller MD, Gao Z, Drew RC, et al. Effect of cold air inhalation and isometric exercise on coronary blood flow and myocardial function in humans. J Appl Physiol (1985) 2011;111:1694-702.

3. Janardhanan R, Henry Z, Hur DJ, et al. The snow-shoveler's ST elevation myocardial infarction. Am J Cardiol 2010;106:596-600.

4. Sheldahl LM, Wilke NA, Dougherty SM, et al. Effect of age and coronary artery disease on response to snow shoveling. J Am Coll Cardiol 1992;20:1111-7.

5. Spielberg C, Falkenhahn D, Willich SN, et al. Circadian, day-of-week, and seasonal variability in myocardial infarction: comparison between working and retired patients. Am Heart J 1996;132:579-85.

6. Auger N, Potter BJ, Smargiassi A, et al. Association between quantity and duration of snowfall and risk of myocardial infarction. CMAJ 2017;189:E235-42.

7. Glass RI, Wiesenthal AM, Zack MM, et al. Risk factors for myocardial infarction associated with the Chicago snowstorm of Jan. 13-15, 1979. JAMA 1981;245:164-5.

8. Gerber Y, Jacobsen SJ, Killian JM, et al. Seasonality and daily weather conditions in relation to myocardial infarction and sudden cardiac death in Olmsted County, Minnesota, 1979 to 2002. J Am Coll Cardiol 2006;48:287-92.

9. Baker-Blocker A. Winter weather and cardiovascular mortality in MinneapolisSt. Paul. Am J Public Health 1982;72:261-5.

10. Southern DA, Knudtson ML, Ghali WA; APPROACH Investigators. Myocardial infarction on snow days: incidence, procedure, use and outcomes. Can J Cardiol 2006;22:59-61.

11. Wong HT, Chiu MY, Wu CS, et al.; Senior Citizen Home Safety Association. The influence of weather on health-related help-seeking behavior of senior citizens in Hong Kong. Int J Biometeorol 2015;59:373-6.

\section{Competing interests: None declared.}

This article was solicited and has not been peer reviewed.

Affiliations: University Health Network Cardiovascular Prevention and Rehabilitation Program, Toronto Rehabilitation Institute - Uni- versity Health Network, Institute for Clinical Evaluative Sciences; Departments of Medicine and Health Policy, Management and Evaluation, University of Toronto, Toronto, Ont.

Acknowledgement: David Alter is a Career Investigator with the Heart and Stroke Foun- dation of Ontario and is supported by a Research Chair in Cardiovascular and Metabolic Rehabilitation, Toronto Rehabilitation Institute-University Health Network.

Correspondence to: David Alter, david.alter@ices.on.ca 